\title{
THE EFFECT OF SELECTED CONDITIONS IN A THERMOFORMING PROCESS ON WALL THICKNESS VARIATIONS
}

\author{
Emil Sasimowski ${ }^{1}$ \\ 1 Lublin University of Technology, Department of Polymer Processing, Nadbystrzycka 36 Str., 20-618 Lublin, \\ Poland, e-mail: e.sasimowski@pollub.pl
}

Received: 2017.05.16

Accepted: 2017.11.01

Published: 2017.12.05

\begin{abstract}
The paper reports the results of a study on the effect of selected conditions in a thermoforming process for thin polystyrene sheet by vacuum assisted drape forming on the wall thickness non-uniformity of finished parts. The investigation was performed using Statistica's DOE module for three variables: temperatures in the external and internal zones of the heater as well as heating time of the plastic sheet. The results demonstrate that the wall thickness in the finished parts at the measuring points is primarily affected by the heating time and the temperature in the internal zone of the heater, while the temperature in the external zone only affects some regions of the finished part. The results demonstrate that a short heating time, and hence, a lower temperature of the plastic sheet lead to a more uniform deformation of both the bottom and the side walls of the finished part, and as a consequence, to smaller variations in the wall thickness. Shortening the heating time is, however, limited by the necessity of accurate reproduction of the shape of the finished part.
\end{abstract}

Keywords: processing technologies, thermoforming, vacuum assisted drape forming, thickness distribution.

\section{INTRODUCTION}

Thermoforming is a process of stretching thermoplastic sheets and plates. It is mainly used for disposable packaging (containers, cups, trays) as well as structural elements of various devices (refrigerator inside walls, casings, switch boards). With this process, a thermoplastic plate or sheet is plasticized in a forming mold to generate tensile stresses which cause its plastic deformation and adherence to the mold cavity; after that, the finished part is cooled and released.

Compared to other processing methods, thermoforming offers a number of advantages including relatively low processing temperature and forming pressure, as well as low costs of tools and devices. Processing devices are highly efficient and unit costs of produced parts are much lower, compared to those of other manu- facturing techniques [18]. Although the practical aspects of this process have been relatively thoroughly investigated, thermoforming is still the subject of numerous research works and studies for processing plants $[5,7,13,14,16-18]$.

In thermoforming, the plastic is subjected to varied stresses and hence undergoes deformation, particularly in the bottom and side walls of the finished part. This leads to the non-uniformity of its wall thickness, which is a critical problem in stretching $[2,10]$.

Given high requirements in this field, it is a common practice to combine several forming methods in one process. One of such widely used methods is vacuum assisted drape forming which consists in forcing the plastic sheet against the male mold in room or higher temperatures. The bottom of the finished part corresponds to the area of the male mold which has a direct impact on the plastic, while the sides are 


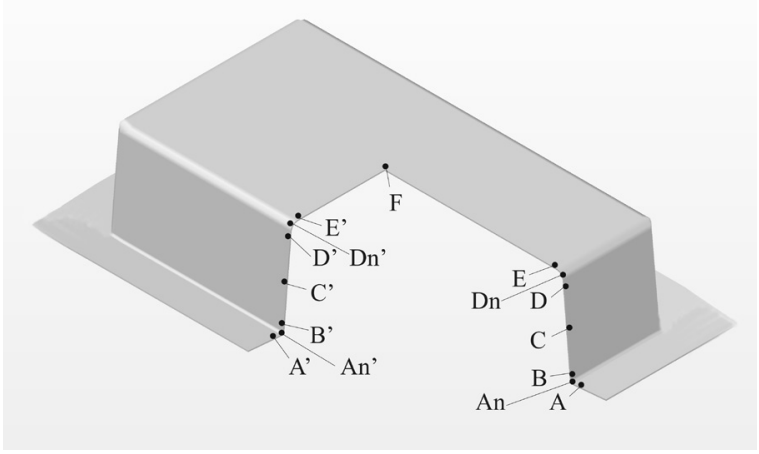

Fig. 1. Schematic design of the finished part and the wall thickness measuring points in the longitudinal section $\mathrm{A}-\mathrm{F}$ and in the cross section $\mathrm{A}^{\prime}-\mathrm{E}$ '

subjected to considerable free stretching due to the impact of low-pressure air (vacuum forming) or high-pressure air (overpressure forming).

This study investigates such a combination of these stretching methods. It analyses the effect of selected conditions of a thermoforming process for polystyrene sheet by vacuum assisted drape forming on the temperature of the tested plastic and the wall thickness distribution of the finished part. The schematic design of the finished part and the wall thickness measuring points is illustrated in Fig. 1.

\section{EXPERIMENTAL PROCEURE}

\section{Test stand}

Test samples were produced by vacuum assisted drape forming using a movable male mold on the PEX B-3 F test stand for stretching (Fig. 2). This test stand comes with a heater with HTS ceramic infrared radiators which form two zones: the external zone comprising the circumferential part of the heated region of the plastic sheet and the internal zone corresponding to the central part of this region (Fig. 3). The radiators are distanced from the surface of the heated plastic sheet by $130 \mathrm{~mm}$. On the inside circumference of the clamp frame there are reflectors which compensate for any heating non-uniformity due to uneven infrared rays penetration of individual regions of the plastic sheet. The tests were performed using an MDF male mold in the shape of truncated pyramid with a 340x190 mm rectangular base, a height of $80 \mathrm{~mm}$, and a top of $300 \times 150$ $\mathrm{mm}$. The depth-of-draw ratio of the male mold, $\mathrm{k}$, was set to 0.53 .

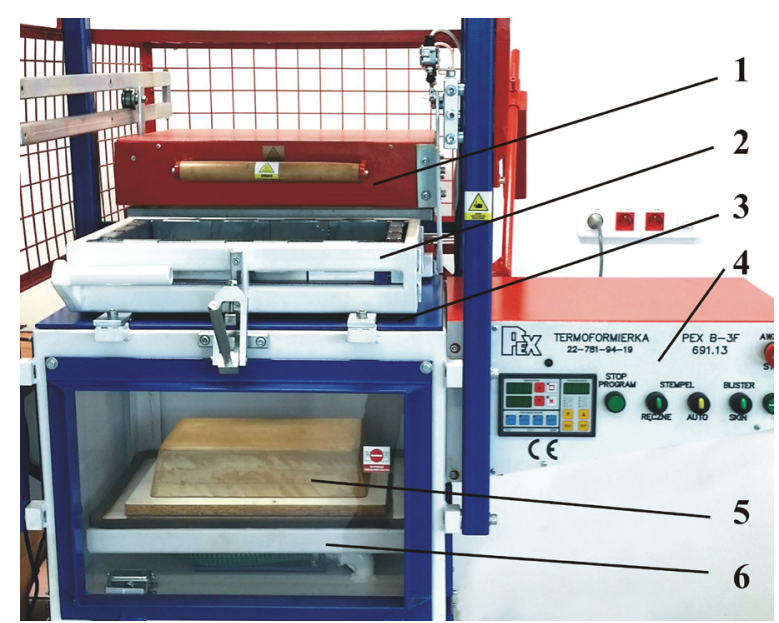

Fig. 2. Test stand for stretching PEX B-3 F:

1 - heater, 2 - clamp frame, 3 - fixed table, 4 - control system, 5 - male mold, 6 - movable table

The temperature of the plastic sheet immediately after heating was measured by the infrared method prior to stretching. This method is used in polymer processing primarily for measuring the temperature of both finished parts and processing tools $[3,6,9,15,19]$. The measurements were made using the V-20 II ER005-10 infrared camera from VIGO System S.A. and the Therm V 20 software.

Based on the result of infrared studies reported in the literature [11] and preliminary measurements, the coefficient of emissivity $\varepsilon$ was set to 0.84 .

The wall thickness of the finished parts was measured with an accuracy of 0,001 $\mathrm{mm}$ using an electronic micrometer with a flat or spherical end depending on the measuring point.

\section{Methods}

The tests were performed on a $0.5 \mathrm{~mm}$ thick polystyrene flat sheet used for stretching manufactured by P.P.H.U Petroplast Ltd.

The process for the plastic sheet was described by the following variables:

- temperature in the external zone of the heater $\mathrm{t}_{\mathrm{z}},{ }^{\circ} \mathrm{C}$,

- temperature in the internal zone of the heater $\mathrm{t}_{\mathrm{w}},{ }^{\circ} \mathrm{C}$,

- heating time T, s.

Constant parameters included:

- vacuum time - $6 \mathrm{~s}(2 \mathrm{hPa})$,

- cooling time - $5 \mathrm{~s}$,

- duration and frequency of compressed air impulses for separating finished part from male mold - 1s, $2 \mathrm{~Hz}$. 


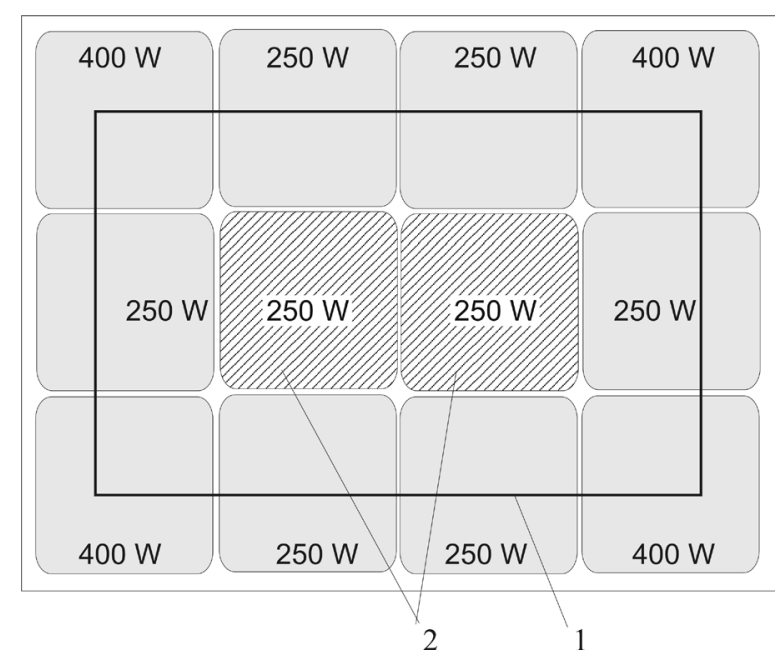

Fig. 3. Schematic design of the heating design: $1-$ clamp frame restraining heating region, 2 - radiators forming internal zone; power of individual radiators is marked in the figure
Table 1. Independent variables

\begin{tabular}{|c|c|c|c|}
\hline Set & $\begin{array}{c}\text { Internal } \\
\text { zone } \\
\text { temperature } \\
\mathrm{T}_{\mathrm{w}}\left[{ }^{\circ} \mathrm{C}\right]\end{array}$ & $\begin{array}{c}\text { External zone } \\
\text { temperature } \\
\mathrm{T}_{\mathrm{z}}\left[{ }^{\circ} \mathrm{C}\right]\end{array}$ & $\begin{array}{c}\text { Heating time } \\
\mathrm{T}[\mathrm{s}]\end{array}$ \\
\hline 1 & 400 & 400 & 18 \\
\hline 2 & 400 & 400 & 26 \\
\hline 3 & 400 & 440 & 18 \\
\hline 4 & 400 & 440 & 26 \\
\hline 5 & 440 & 400 & 18 \\
\hline 6 & 440 & 400 & 26 \\
\hline 7 & 440 & 440 & 18 \\
\hline 8 & 440 & 440 & 26 \\
\hline 9 & 386 & 420 & 22 \\
\hline 10 & 454 & 420 & 22 \\
\hline 11 & 420 & 386 & 22 \\
\hline 12 & 420 & 454 & 22 \\
\hline 13 & 420 & 420 & 15 \\
\hline 14 & 420 & 420 & 29 \\
\hline $15 \div 20$ & 420 & 420 & 22 \\
\hline$(\mathrm{C})$ & & & \\
\hline
\end{tabular}

The measurements were made in compliance with a rotable central composite design with the star point distance $\alpha$ set to 1.6818 , prepared using Statistica $12[1,8,12]$. According to the recommendations given in the literature [1], the measurements were repeated six times in the central point, leading to a total set of 20 runs that are listed in Table 1 . The range of independent variables $t_{z}, t_{w}$ and $T$ for the design was determined based on preliminary tests. Regression analysis was used to describe the relationships between the dependent variable $x$ and the tested quantity, and the applied independent variables $t_{z}, t_{w}$, and $\mathrm{T}$ by model equation (1).

$$
\begin{aligned}
& x=\beta_{0}+\beta_{1} t_{w}+\beta_{2} t_{z}+\beta_{3} T+\beta_{11} t_{w}{ }^{2}+\beta_{22} t_{z}^{2}+\beta_{33} T^{2}+ \\
& +\beta_{12} t_{w} t_{z}+\beta_{13} t_{w} T+\beta_{23} t_{z} T
\end{aligned}
$$

where $\beta_{\mathrm{n}}$ are coefficients of the model equations.

The investigated parameters included: the wall thickness of the finished part $(\mathrm{g})$ at the measuring points given in Fig. 1, as well as the distributions of temperatures $\left(t_{x}\right)$ and $\left(t_{y}\right)$ over the surface of the plastic sheet measured immediately after heating along the lines corresponding to the longitudinal and cross symmetry axes, respectively.

\section{Results and discussion}

The study investigated the effect of selected variables on the wall thickness of finished parts at selected measuring points. The results demonstrate that the lowest wall thickness occurs on the external edge of the finished part (An, An') in the longitudinal (Fig. 4) and cross (Fig. 5) sections, then in the area that is adjacent to this edge (B, B'), and finally in the central region of the side wall (C, C'). The polymer in this region of the finished part undergoes the highest thinning because it is the last one to contact the male mold. The highest wall thickness of the finished part is observed at points D, D', Dn, Dn', E, E' and F. This results from the fact that this region of the plastic sheet is the first to contact the surface of the male mold and - given its rapid cooling - its further participation in the forming process is limited.

The Pareto analysis results demonstrate that the wall thickness in the longitudinal section at point A is only affected by the heating time, while at points $\mathrm{An}$ and B it is also influenced by the temperature in the internal zone of the heater, and at point $\mathrm{C}$ - also by the temperature in the external zone and the interaction between the external zone temperature and heating time, and between the temperatures in the external and internal zones. At points D, DN and $\mathrm{E}$ the wall thickness is the most significantly affected by the interaction between the temperature of the internal zone and the heating time, and at point $\mathrm{F}$ it is additionally affected by the heating time. 


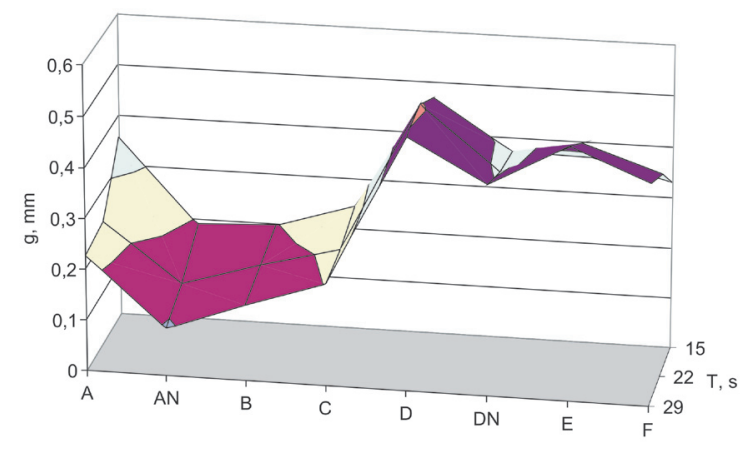

Fig. 4. Wall thickness at the measuring points in the longitudinal section of the finished part versus heating time when the temperature in the external and internal zones of the heater is $420^{\circ} \mathrm{C}$

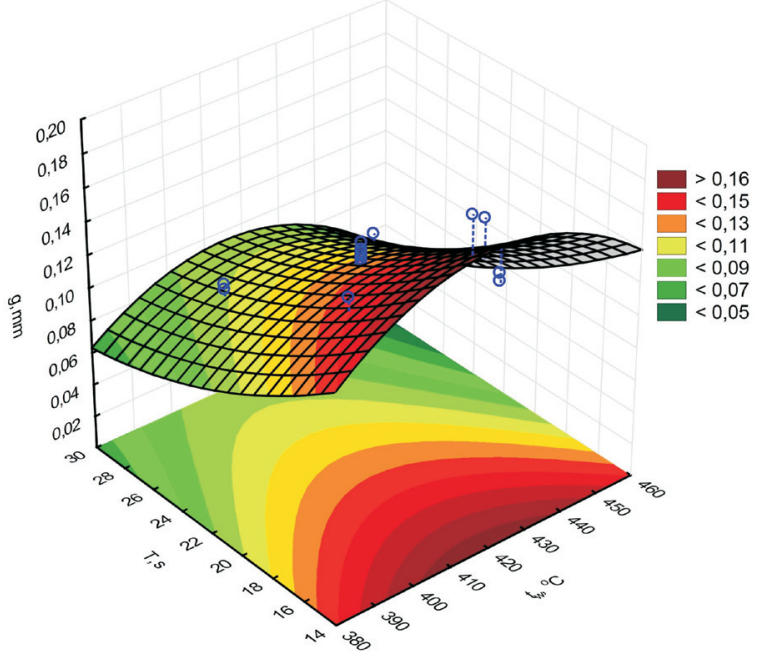

Fig. 6. Wall thickness of the finished part (g) at point An versus the temperature in the internal zone $\left(\mathrm{t}_{\mathrm{w}}\right)$ and heating time $(\mathrm{T})\left(\right.$ at $\left.\mathrm{t}_{\mathrm{z}}=420^{\circ} \mathrm{C}\right)$

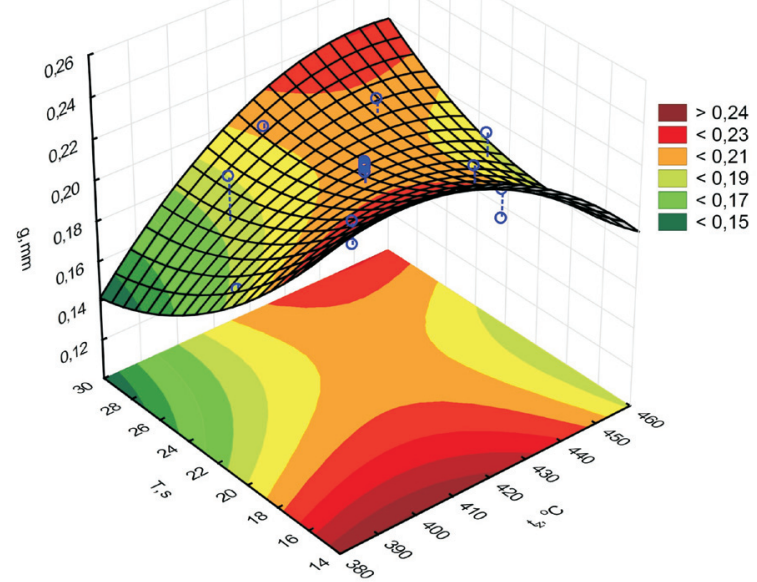

Fig. 8. Wall thickness $(\mathrm{g})$ at point $\mathrm{C}$ versus temperature in the external zone $\left(\mathrm{t}_{\mathrm{z}}\right)$ and heating time $(\mathrm{T})$

$$
\text { (at } \mathrm{t}_{\mathrm{w}}=420^{\circ} \mathrm{C} \text { ) }
$$

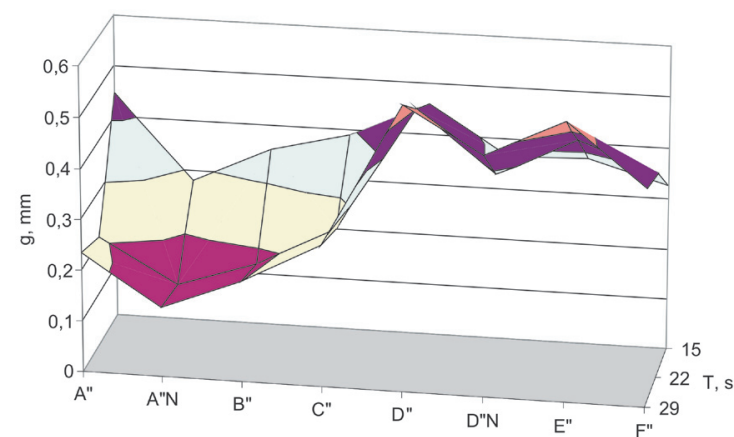

Fig. 5. Wall thickness at the measuring points in the cross section of the finished part versus heating time when the temperature in the external and internal zones of the heater is $420^{\circ} \mathrm{C}$

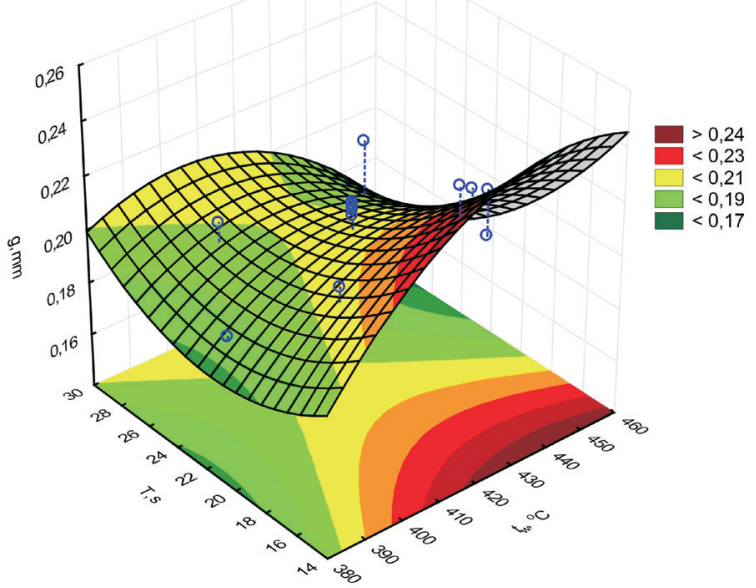

Fig. 7. Wall thickness of the finished part (g) at point $\mathrm{C}$ versus temperature in the internal zone $\left(\mathrm{t}_{\mathrm{w}}\right)$ and heating time $(\mathrm{T})\left(\right.$ at $\left.\mathrm{t}_{\mathrm{z}}=420^{\circ} \mathrm{C}\right)$

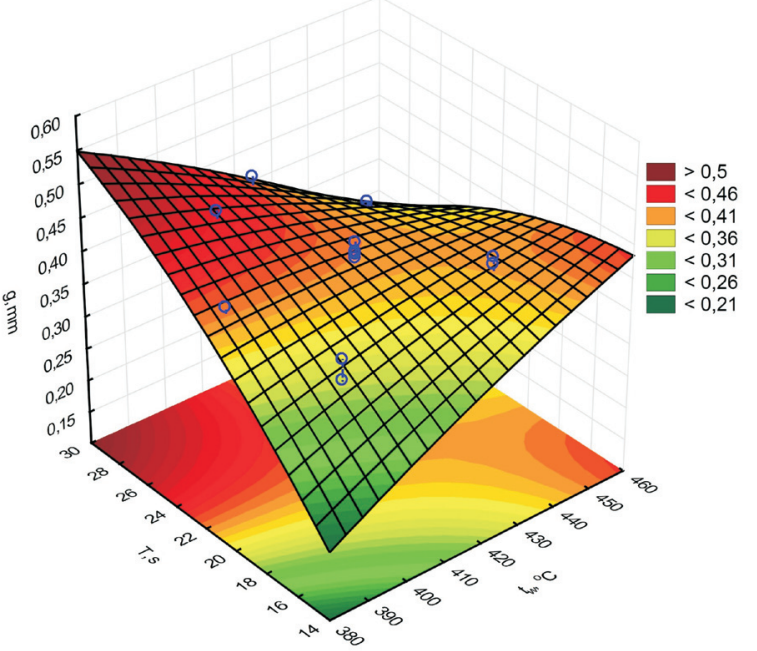

Fig. 9. Wall thickness at point $\mathrm{F}$ versus temperature in the internal zone (tw) and heating time (T) (at $\mathrm{t}_{\mathrm{z}}=420^{\circ} \mathrm{C}$ ) 
The effect of the above variables on the wall thickness in the longitudinal section at the measuring points is illustrated in Figs. 6-9. As can be seen in Fig. 6, the wall thickness at point An is the highest for the internal zone temperature $\left(\mathrm{t}_{\mathrm{w}}\right)$ close to $420^{\circ} \mathrm{C}$, but it decreases with increasing the heating time $(\mathrm{T})$. A similar effect was observed at point $\mathrm{B}$.

The wall thickness of the finished part at point $\mathrm{C}$ (Fig. 7) is also the highest at the shortest heating time $(\mathrm{T})$ and at the internal zone temperature (tw) that is equal to or higher than $420^{\circ} \mathrm{C}$. To obtain the highest wall thickness, the temperature in the external zone $\left(\mathrm{t}_{\mathrm{z}}\right)$ should be equal to or lower than $420^{\circ} \mathrm{C}$, as shown by the relationship given in Figure 8.

A different observation can be made regarding the wall thickness at point $\mathrm{D}$ located on the side wall at the bottom edge, as well as at points $\mathrm{E}$ and $\mathrm{F}$ located on the bottom of the finished part. At low temperatures in the internal zone $\left(\mathrm{t}_{\mathrm{w}}\right)$, the wall thickness increases with increasing the heating time (Fig. 9), while it decreases at high temperatures.

The study also involved a Pareto analysis of the effect of the tested variables on the wall thickness in the cross section of the finished part. The results of point A' reveal a significant effect of the heating time and its interaction with the temperature in the internal zone, while the results of points An', B' and C' indicate that the wall thickness is significantly affected only by the heating time, while the results of points D' and Dn' are also strongly affected by the internal temperature and its interaction with the external temperature. The results of point E' reveal a significant effect of the heating time and the internal zone temperature on the wall thickness of the finished part.

The effect of the variable parameters on the cross-sectional wall thickness at the measuring points is illustrated in Figures 10-13.

At points A', An' and B' the heating time has a similar effect on the wall thickness of the finished part. The highest wall thickness is observed for the shortest heating time. With increasing heating time, the wall thickness of the finished part decreases; after that, having reached the minimum in the time interval $\mathrm{T}=24-28 \mathrm{~s}$, it begins to slighly increase (Fig. 10). A similar observation is made regarding the wall thickness at point $\mathrm{A}$ in the longitudinal section of the finished part.

Heating time has a similar effect on the wall thickness at point $\mathrm{C}$; what we can additionally ob- serve here is the impact of the internal zone temperature (Fig. 11). The highest wall thickness is observed at the lowest and highest temperatures (tw) for the shortest and longest heating time (T), respectively.

An increase in the heating time at points D' and Dn' leads to an increase in the wall thickness at the lowest and highest temperatures in the internal zone $\left(\mathrm{t}_{\mathrm{w}}\right)$ (Fig. 12). The relationship between the wall thickness at these measuring points and the temperatures in the internal and external zones of the heater is illustrated in Figure 13. The highest wall thickness is observed at the lowest and highest temperatures (tw) for the highest and lowest temperatures $\left(\mathrm{t}_{\mathrm{z}}\right)$, respectively.

The results of thermal measurements are in a form of curves corresponding to the temperature of the plastic sheet after heating in the area bounded by the clamp frame. For the selected heating conditions, the variations in the temperature of the plastic sheet measured along the axis of longitudinal symmetry of the plastic sheet are shown in Figure 14, whereas those measured along the axis of transverse symmetry are shown in Figure 15.

The results of the measurements made along the sheet demonstrate that, despite the variations in the temperature in the internal and external zones of the heater, the temperature remains almost constant, with the exception of the regions at the clamp frame. Besides the heating time, this temperature is significantly affected by the temperature of the internal zone of the heater. A significant decrease in the temperature of the plastic sheet occurring in the vicinity of the clamp frame is caused by a phenomenon (described in the literature [4]) consisting in restraining by the frame the access of infrared rays to this region, which cannot be entirely compensated for by the applied reflectors.

Significant variations are observed for the temperature across the plastic sheet. The temperature decreases in the central region of the sheet, which can particularly be observed at a longer heating time. In this case, the temperature of the plastic sheet is also considerably affected by the temperature in the internal zone of the heater.

The observed variations in the temperature of the plastic sheet depending on the applied heating conditions have a direct impact on the sheet's plasticization and deformation, and hence on the wall thickness of the finished part.

It has been found that the temperature in the internal zone of the heater has a significant effect 


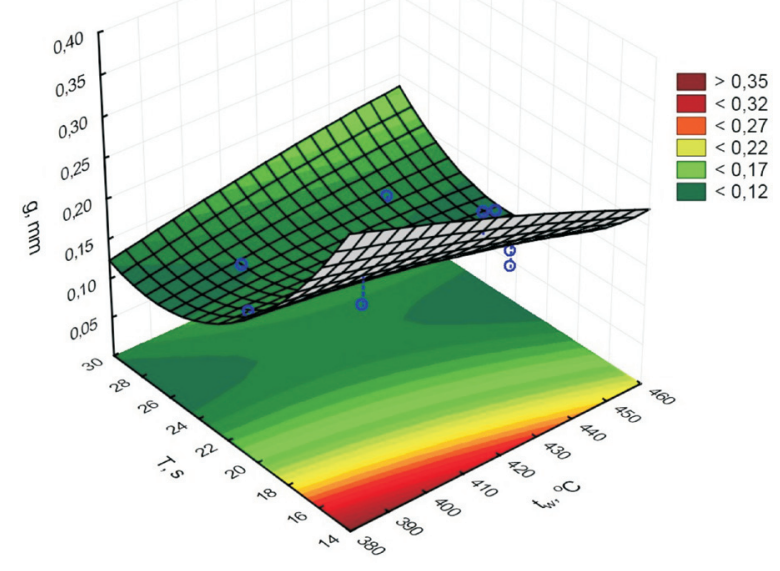

Fig. 10. Wall thickness of the finished part (g) at point An' versus temperature in the internal zone $\left(\mathrm{t}_{\mathrm{w}}\right)$ and heating time $(\mathrm{T})\left(\right.$ at $\left.\mathrm{t}_{\mathrm{z}}=420^{\circ} \mathrm{C}\right)$

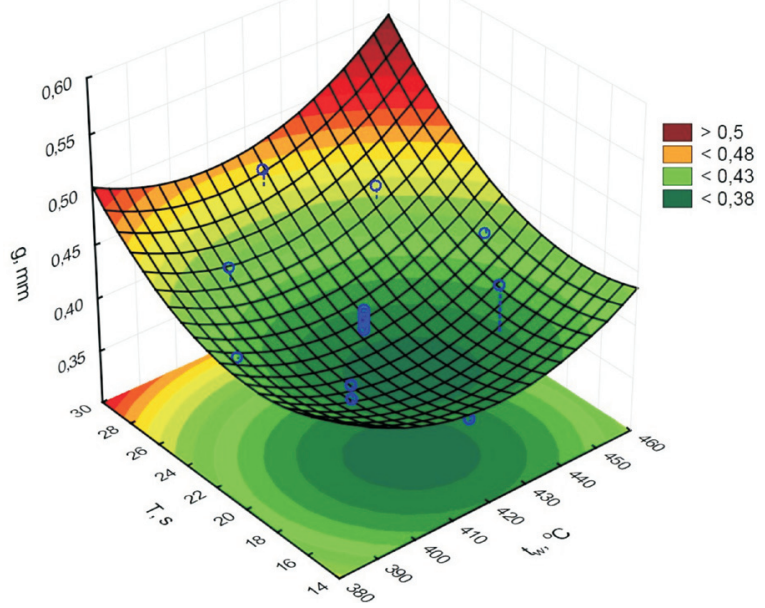

Fig. 12. Wall thickness of the finished part (g) at point Dn' versus temperature in the internal zone $\left(\mathrm{t}_{\mathrm{w}}\right)$ and heating time $(\mathrm{T})\left(\right.$ at $\left._{\mathrm{z}}=420^{\circ} \mathrm{C}\right)$

on the temperature of the plastic sheet, and as a result, on the wall thickness of the finished parts, as confirmed by the Pareto analysis results. This effect results from the design of the heater (Fig. 3), particularly by the position of the radiators relative to the plastic sheet and the clamp frame.

\section{CONCLUSIONS}

The results demonstrate that the distribution of the temperature of the polystyrene sheet and hence the non-uniformity of wall thickness of the

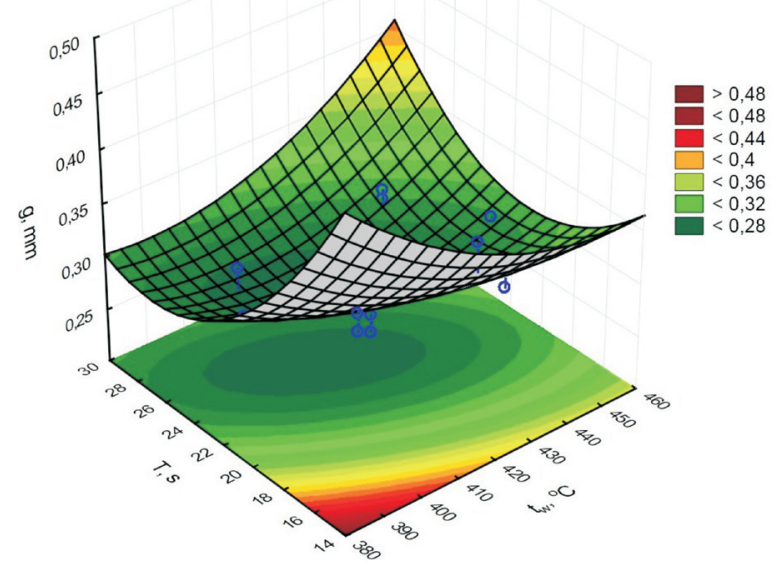

Fig. 11. Wall thickness of the finished part (g) at point $\mathrm{C}^{\prime}$ versus temperature in the internal zone $\left(\mathrm{t}_{\mathrm{w}}\right)$ and heating time $(\mathrm{T})\left(\right.$ at $\left.\mathrm{t}_{\mathrm{z}}=420^{\circ} \mathrm{C}\right)$

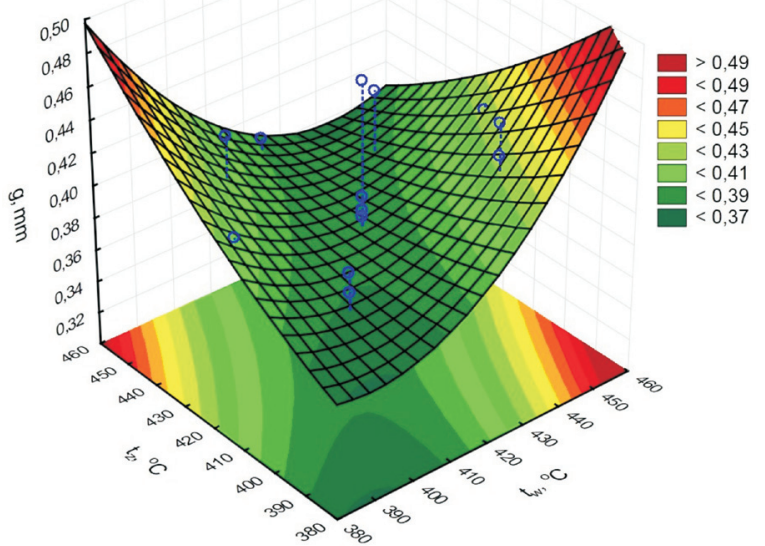

Fig. 13. Wall thickness of the finished part $(g)$ at point Dn' versus temperatures in the internal $\left(\mathrm{t}_{\mathrm{w}}\right)$ and external $\left(\mathrm{t}_{\mathrm{z}}\right)$ zones $($ at $(\mathrm{T})=22 \mathrm{~s})$

finished part are significantly affected by the heating time and the temperature in the internal zone of the heater. Given the location of the external zone relative to the heated region of the sheet, the temperature in this zone has a significant effect on the finished part's wall thickness in the centre of the longitudinal section and in the bottom edge of the cross section. The location of the internal and external heater zones is defined through the hardware of the test stand for stretching.

The undesired non-uniformity of wall thickness of the finished part at the measuring points increases with increasing the heating time. This 


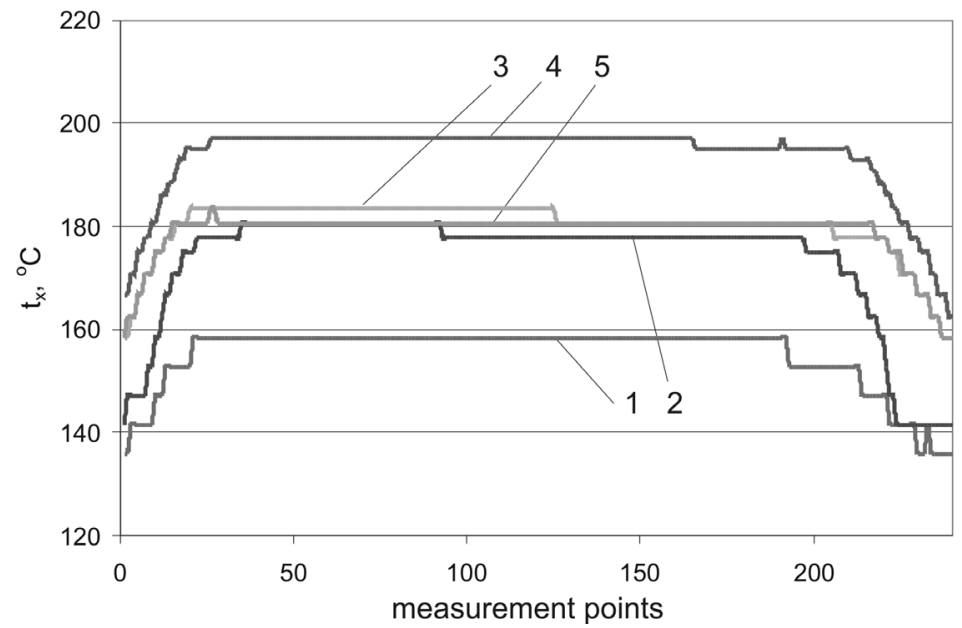

Fig. 14. Temperature $\left(\mathrm{t}_{\mathrm{x}}\right)$ of the sheet surface along the longitudinal symmetry axis after heating at: (1) $-\mathrm{T}=18 \mathrm{~s} ;(2)-\mathrm{T}=26 \mathrm{~s}$ at $\mathrm{t}_{\mathrm{w}}=400^{\circ} \mathrm{C}, \mathrm{t}_{\mathrm{z}}=440^{\circ} \mathrm{C}$; (3) $-\mathrm{T}=18 \mathrm{~s} ;$; (4) $-\mathrm{T}=26 \mathrm{~s}$ at $\mathrm{t}_{\mathrm{w}}=440^{\circ} \mathrm{C}, \mathrm{t}_{\mathrm{z}}=400^{\circ} \mathrm{C}$;

(5) $-\mathrm{T}=18 \mathrm{~s}$ at $\mathrm{t}_{\mathrm{w}}=\mathrm{t}_{\mathrm{z}}=440^{\circ} \mathrm{C}$

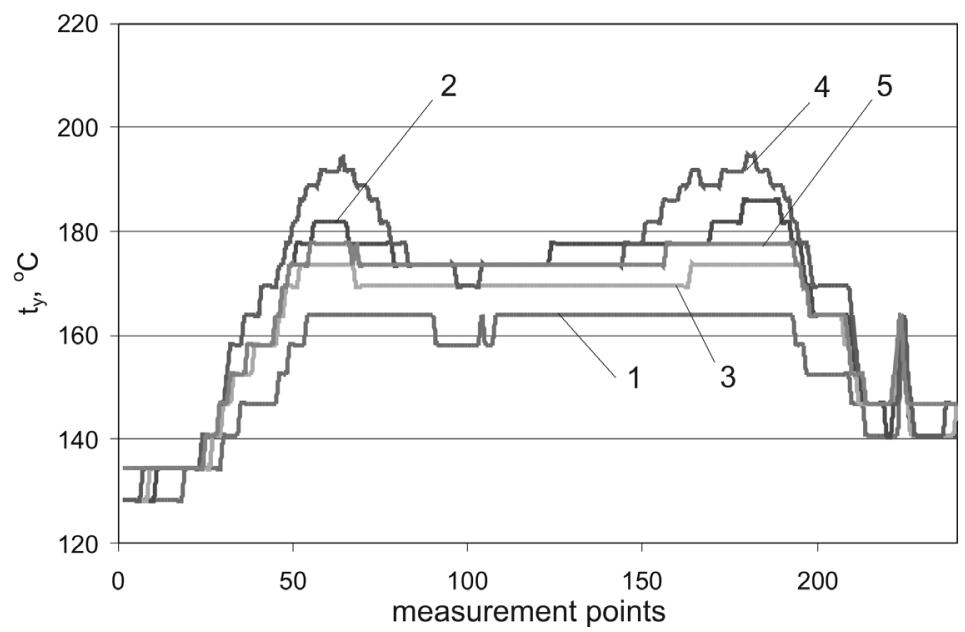

Fig. 15. Temperature $\left(t_{y}\right)$ of the sheet surface along the lateral symmetry axis; denotations as in Figure 14

results from a non-uniform deformation of individual regions of the plastic sheet during stretching. With increasing the heating time and hence the temperature of the plastic sheet, the deformation of the part's bottom gradually decreases and eventually disappear in contrast to the deformation of the side walls of the finished part. A short heating time and, as a result, a low temperature of the plastic sheet cause deformation of the finished part's bottom and side walls. The shortening of the heating time is, however, limited by the necessity of accurate reproduction of the male mold in the area of the external edge of the finished part.

The problem of optimization of thermoforming conditions will be discussed in a separate publication.

\section{REFERENCES}

1. Antony, J. 2014. Design of Experiments for Engineers and Scientists, Elsevier, London.

2. Engelmann, S. 2012. Advanced thermoforming: methods, machines and materials, applications and automation, John Wiley \& Sons, UK. Chichester.

3. Golzar, M., et al. 2004. Online temperature measurement and simultaneous diameter estimation of fibers by thermography of the spinline in the melt spinning process", Adv. Polym. Technol., 23, 176-185.

4. Gruenwald, G. 1998. Thermoforming: A Plastics Processing Guide, Second edition, Technomic Publishing, Lancaster.

5. Hopmann, Ch., Martens, J., 2015. Thermoformen: Kühlzeitreduktion durch wassernebel. Kunstst- 
offe, 8, 67-69.

6. Kaynak, A., Håkansson, E., 2005. Generating heat from conducting polypyrrole-coated PET fabrics", Adv. Polym. Technol., 24, 194-207.

7. Klein, P.W. 2009. Fundamentals of plastic thermoforming, Synthesis lectures on materials engineeering, Morgan \& Claypool Publishers.

8. Mead, R., et al. 2012. Statistical Principles for the Design of Experiments: Applications to Real Experiments. Cambridge University Press, Cambridge.

9. Menary, G.H., et al. 2012. Biaxial deformation and experimental study of PET at conditions applicable to stretch blow molding. Polym. Eng. Sci., 52, 671-688.

10. Min S.C., et al. 2011. Thermoformed container wall thickness effects on orange juice quality", Journal of Food Processing and Preservation, 6, 758-766.

11. Minkina, W., Dudzik, S. 2009. Infrared Thermography: Errors and Uncertainties, Wiley \& Sons.

12. Montgomery, D.C. 2009. Design and Analysis of Experiments, 7 th. Edition, Wiley\&Sons.
13. Throne, J.L. 1996. Technology of thermoforming, Hanser Publishers, Munich.

14. Throne, J.L. 2008. Understanding thermoforming, Hanser Publishers: Munich.

15. Tor-Świątek, A., Samujło, B. 2013. Use of thermovision research to analyze the thermal stability of microcellular extrusion process of poly(vinyl chloride)", Maintenance and Reliability, 15, 58-61.

16. Żenkiewicz, M., Lutomirski, S. 2006. Effect of heat on some properties of surface layer of polymeric films used for vacuum forming", Polimery, 51, 442-448.

17. Żenkiewicz, M., Richert, J. 2009. Thermoforming of polylactide nanocomposite films for packaging containers", Polimery, 54, 299-302.

18. Żenkiewicz, M., Szach, A. 2010. Recent developments in the thermoforming of polimeric materials", Polimery, 55, 337-350.

19. Zimmer, J., et. al. 2015. Experimental investigation and numerical simulation of liquid supported stretch blow molding”. Polym. Eng. Sci., 55, 933-944. 